\title{
Tendencias en investigación sobre duelo y sentimientos morales en sobrevivientes del conflicto armado colombiano
}

\author{
Trends in research on grief and moral feelings in survivors of the Colombian armed \\ conflict
}

\section{Tendências de pesquisa sobre luto e sentimentos morais em sobreviventes do conflito armado colombiano}

\author{
Jair Eduardo Restrepo Pineda ${ }^{a^{*}} \mid$ Alis Dahiana Bedoya-Olaya ${ }^{b}$ \\ a https://orcid.org/0000-0002-3959-4550 \\ ${ }^{\mathrm{b}}$ https://orcid.org/0000-0002-4756-5987 \\ Corporación Universitaria Minuto de Dios, Colombia
}

- Fecha de recepción: 2020-02-09

- Fecha concepto de evaluación: 2020-04-29

- Fecha de aprobación: 2020-05-08 https://doi.org//0.22335/rlct.v12i2.1 I 49
Para citar este artículo / To reference this article / Para citar este artigo: Restrepo Pineda, J. E., \& Bedoya-Olaya, A. D. (2020). Tendencias en investigación sobre duelo y sentimientos morales en sobrevivientes del conflicto armado colombiano. Revista Logos Ciencia \& Tecnología, I 2(2), 98-I I I. https://doi.org/ I0.22335/rlct.v| 2i2. I I 49

\section{RESUMEN}

El presente artículo realiza una revisión documental sobre las tendencias investigativas relacionadas con el duelo y los sentimientos morales en víctimas del conflicto armado colombiano. El estudio se desarrolló a partir de dos categorías de análisis, el duelo y los sentimientos morales, enmarcadas en las experiencias de vida de los sobrevivientes. Se evidenció un incremento del interés por comprender el proceso de duelo desde los diferentes marcos en los que se encuentra la víctima y el impacto que generan los actuales programas de intervención psicosocial en la transformación emocional de los sobrevivientes. Asimismo, se identificó una relación directa entre los sentimientos morales y las experiencias emocionales de las víctimas frente al hecho, como es el caso del proceso de duelo.

Palabras clave: moral, víctima de guerra, conflicto armado, bienestar social, justicia social 


\section{ABSTRACT}

This article performs a documentary review on the investigative trends related to mourning and moral feelings in victims of the Colombian armed conflict. The study was developed from two categories of analysis, mourning and moral feelings, framed in the life experiences of the survivors. There was evidence of an increase in interest in understanding the mourning process from the different frameworks in which the victim finds him/herself and the impact that current psychosocial intervention programs generate on the emotional transformation of survivors. Likewise, a direct relationship between moral feelings and the emotional experiences of the victims in relation to the event was identified, as is the case of the mourning process.

Keywords: moral, victim of war, armed conflict, social welfare, social justice

\section{RESUMO}

Este artigo faz uma revisão documental das tendências investigativas relacionadas ao luto e aos sentimentos morais das vítimas do conflito armado colombiano. $O$ estudo foi desenvolvido a partir de duas categorias de análise, luto e sentimentos morais, enquadrados nas experiências de vida dos sobreviventes. Houve evidência de um aumento no interesse em entender o processo de luto a partir dos diferentes quadros em que a vítima se encontra e o impacto que os atuais programas de intervenção psicossocial geram na transformação emocional dos sobreviventes. Da mesma forma, foi identificada uma relação direta entre os sentimentos morais e as experiências emocionais das vítimas em relação ao fato, como é o caso do processo de luto.

Palavras-chave: moral, vítima de guerra, conflito armado, bem-estar social, justiça social

El conflicto armado en Colombia ha involucrado diferentes actores, entre ellos, las guerrillas, los paramilitares, los narcotraficantes, la sociedad civil, el Gobierno y las Fuerzas Armadas, dado que es resultado de la división entre dichos actores y las tensiones que de allí se derivan. Uno de los periodos atenuantes del conflicto se dio entre 1946 y 1966, producto de la disociación entre los partidos políticos Liberal y Conservador (Yaffe, 20I I). Asimismo, se ha identificado que, en medio de las múltiples causas, existen perspectivas que indican cómo puede deberse a la desigualdad y la injusticia, la codicia y la disputa por el control y el manejo del capital económico que proviene de la explotación de los recursos naturales (Yaffe, 20l I).

Además del conocimiento de las causas, algunos enfoques de análisis se han ocupado por descubrir las condiciones que permitan reducir el conflicto armado de tal manera que sea posible la supresión del accionar de la violencia como único recurso movilizador de cambio. Otros, por su parte, tienen por objeto abordar las consecuencias de la violencia; entre estos enfoques se encuentra la "investigación para la paz" (Comins, 2015) y la revisión del lugar de las víctimas' o "victimología” (Bustamante, 2017). Este último

I En este artículo se empleará indistintamente el uso de los términos víctimas y sobrevivientes, a fin de hacer referencia a las personas que han sufrido, padecido o experimentado daños materiales y emocionales a raíz de contextos de guerra o conflicto armado. enfoque introduce a las víctimas como nuevos actores que, si bien no son generadoras del conflicto, se convierten en receptores de sus efectos. En este sentido, son estas el eje central del presente artículo.

Las cifras nacionales sobre el conflicto armado colombiano señalan que hasta octubre del 2019 el número de víctimas registradas era de 8524910 (Unidad para la Atención y Reparación Integral a las Víctimas [UARIV], 2019), que equivale aproximadamente al 17,6\% de los habitantes del país. Aunque estas cifras no reflejan la totalidad de los daños causados por el conflicto armado sí dan cuenta de la presencia de un número considerable de personas que reivindican el derecho a conocer la verdad con relación a los hechos violentos, así como la de obligación por parte del Estado de brindar asistencia, apoyo social, político, económico y acceso a medidas de protección para las víctimas.

A raíz de la necesidad de propiciar un espacio para las víctimas en el que se conozcan sus vivencias y los avances en relación con las acciones orientadas a su acompañamiento y la reparación integral, se ha presentado en los últimos años una serie de estudios que se ocupan de visibilizar dichas experiencias y analizar, desde diferentes aristas, las secuelas y los efectos que dejan los hechos victimizantes. Tal es el caso de los estudios que se ocupan de las consecuencias características que generan estos en la víctima,

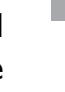


como es el caso de los efectos en la salud mental y los mecanismos que operan positivamente en la superación del hecho, tales como el apoyo social percibido, el liderazgo afectivo y la rehabilitación comunitaria (Echeverri, Moreno, Carrasco, Ferrel \& Ferrel, 20I8; Villa, Londoño, Gallego, Arango \& Rosso, 2016). De esta manera, se producen tendencias investigativas dirigidas a comprender la experiencia subjetiva de los sobrevivientes tales como los procesos de elaboración y resignificación del duelo, convirtiéndose en una categoría de interés en los estudios sobre las secuelas psíquicas generadas por el conflicto.

Así las cosas, el duelo ha sido un factor que ha cobrado relevancia en el propósito de comprender la experiencia subjetiva posterior de las víctimas, y en consonancia con ello surgen intereses investigativos que indagan sobre el carácter propio de este y su relación con el ciclo vital (Guzmán, Fernández \& Villalba, 20l6), así como su vinculación con el hecho victimizante (Díaz, Molina \& Marín, 2015; Zapata, Giraldo, Zuleta \& Montoya, 2015) o con el contexto sociopolítico en que se encuentra la víctima (Rubiano, 20 I7b), para pasar de la experiencia masiva a la experiencia particular en la que se enmarca cada persona. Por tanto, los sobrevivientes "deben atenderse con un enfoque diferencial, que permita la caracterización de sus particularidades subjetivas en cuanto a su ciclo vital, género, pertenencia a grupos étnicos, discapacidad, hecho victimizante, procedencia geográfica, etc." (Obando, Salcedo \& Correa, 2017, p. 385); por ende, el duelo se constituye en un eje fundamental dentro de los procesos de reparación, puesto que conlleva a la distinción de la experiencia singular de la persona para movilizar sus procesos de reparación y elaboración del hecho.

Con relación al duelo, es a partir del siglo $X X$ cuando surge un interés por conceptualizarlo y describirlo, situación que se realiza a través de la definición de fases o etapas en las que se logran encontrar convergencias alusivas a la negación de la pérdida, la conmoción emocional experimentada y el restablecimiento de la persona ante el hecho (Díaz, 2019). Asimismo, estos planteamientos teóricos han servido de soporte para la comprensión del duelo en escenarios específicos, como, por ejemplo, los contextos de guerra.

Según Moreno (20I0), es posible referir cinco marcos conceptuales que definen el duelo: el primero de ellos es el marco psicoanalítico sobre el cual se toma en cuenta la relación de apego con el objeto libidinal. Para Freud (I98I), el duelo es una "reacción ante la pérdida de un ser amado o de una abstracción equivalente: la patria, la libertad, el ideal, etc." (p. 209l), por tanto, está ligado a la ruptura de un vínculo que antes se tenía y ahora no. En segundo lugar, se encuentra el cognitivo conductual, desarrollado por autores como Worden, Rando y Pollock, quienes introducen la noción del sujeto como alguien activo en la experiencia de duelo quien, a su vez, cuenta con los recursos psíquicos para su elaboración, resignificación y adaptación. El tercero es el marco mixto o biopsicosocial dentro del cual se toman en cuenta los procesos físicos y cerebrales en la experiencia de duelo, relacionándolo a eventos como el estrés postraumático y a procesos biológicos. EI cuarto marco es el psicosocial, en el que se incluyen autores como Lindemann, Bowlby, Tizón y Kübler, quienes plantean el duelo como un proceso de adaptación de la persona al medio y su transición psicosocial. Finalmente, está el marco sociológico o sociocultural, desarrollado por teóricos como Robert A. Neimeyer, quien inserta factores tales como el ritualismo, la narrativa y el fortalecimiento de las redes de apoyo para el doliente. No obstante, en el siglo XX, con la publicación de Sigmund Freud de "Duelo y melancolía", se identificó un aumento en estudios sobre la noción del duelo, especialmente para las disciplinas "psi", con lo que se proporcionó un mayor conocimiento y abordaje de este proceso psíquico (Díaz, 2019).

Por otra parte, es importante reconocer que existen innumerables secuelas que los hechos victimizantes dejan en la víctima y sirven para identificarla como tal. En este sentido, uno de los aspectos más relevantes, según la Corte Constitucional colombiana, es el daño, entendido como "el daño moral en sus diversas formas, el daño en la vida de relación [...], así como todas las demás modalidades de daño, reconocidas tanto por las leyes como por la jurisprudencia" (Sentencia C-052-12 de 2012, pár. 4). Este tipo de afectaciones, específicamente el daño moral, impacta también en diferentes áreas de la persona como, por ejemplo, el plano interrelacional, en tanto puede dar lugar a sentimientos particulares sobre el hecho victimizante, los victimarios, la sociedad y el contexto político, lo que a su vez logra afectar las conductas, las actitudes y las posturas propias de los sobrevivientes en escenarios sociales.

Con relación a los sentimientos particulares que pueden tener las víctimas frente al hecho victimizante, a los victimarios o a la sociedad en general, aparece la categoría de los sentimientos morales, la cual fue desarrollada por diferentes disciplinas, principalmente por la filosofía 
moral. Para Smith (1759), los sentimientos morales están ligados a la aprobación o desaprobación de las situaciones - lo que se considera bueno o malo para la persona y, bajo este contenido moral, se manifiestan las emociones. Es este mismo autor quien formula una teoría propia sobre los sentimientos morales, la cual es una de las teorías más representativas sobre el tema. Posteriormente, surgen autores como Martha Nussbaum (20l4), quien argumenta la importancia de considerar la ética y el cultivo público de las emociones mediante la formulación de una teoría de las emociones políticas para el desarrollo de la sociedad. Surgen así perspectivas que relacionan la ética y la moral con la experiencia de las emociones propias y cómo están ligadas a la intersubjetividad o se desarrollan en la colectividad.

En este mismo sentido, los sentimientos morales existen desde el hecho de ser seres en relación. Strawson indica que estos se originan por las relaciones interpersonales (Ortiz, 2015) y afirma que los sentimientos "son como alarmas y sensores que tenemos instalados desde niños y nos alertan en un mundo de conflicto para que reaccionemos ante el mal y nos superemos como personas morales" (Hoyos, 2007, p. 33). Es por esto que estos ocupan un lugar activo en la vida social, por lo que pueden convertirse en un recurso para orientar las acciones y las prácticas sociales y ciudadanas (Quintero \& Mateus, 20I4).

Si bien no se ha encontrado un amplio desarrollo investigativo que se ocupe de indagar en concreto sobre el lugar de la experiencia moral en las víctimas luego de ocurridos los hechos victimizantes, se encuentran estudios que guardan mayor afinidad asociados a sentimientos de carácter moral tales como la rabia, la impotencia y la culpa, los cuales reflejan experiencias emocionales particulares derivadas del acto victimizante (Echeverri et al., 2018). Estos sentimientos, por tanto, requieren de atención para la comprensión de la experiencia de los sobrevivientes y de las posteriores decisiones que toman como consecuencia de su resignificación del hecho.

En consecuencia, surgen algunos interrogantes sobre cuáles son las tendencias en investigación sobre duelo en sobrevivientes del conflicto armado en los últimos años, en la medida en que es una categoría que ha cobrado relevancia para la comprensión de la vivencia singular de la víctima y su transformación personal luego de ocurridos los hechos. Asimismo, sobre cuál es el lugar que ocupan los sentimientos morales dentro de los estudios que indagan sobre el duelo y la experiencia subjetiva de las víctimas, en cuanto generadores de posturas y acciones en los sobrevivientes del conflicto. A fin de responder a estos dos interrogantes este artículo se estructura en dos categorías de análisis. La primera, asociada al duelo en los sobrevivientes del conflicto armado, pretende realizar una aproximación a los enfoques investigativos más utilizados, como, por ejemplo, el sociocultural y el psicosocial. La segunda categoría está relacionada con los sentimientos morales en sobrevivientes del conflicto armado y presenta una conceptualización de estos.

\section{Metodología}

El artículo se elaboró mediante una revisión documental en la que se realizó un análisis bibliográfico de fuentes secundarias tales como artículos de revista, capítulos de libros, libros y tesis de maestría, entre otros, y se perfiló a partir de un enfoque cualitativo y sincrónico.

El diseño metodológico de este estudio se dividió en cinco fases. La primera fue la definición de los descriptores utilizados para la búsqueda y la recuperación de la información, los cuales fueron: víctimas del conflicto, duelo, sentimientos morales y conflicto armado.

La segunda fase tuvo como finalidad la búsqueda de documentos que cumplieran con los siguientes criterios de inclusión: (a) los descriptores seleccionadas en el primer momento; (b) que fueran investigaciones realizadas dentro de un rango de temporalidad que oscila entre el 2014 y el 2019, con el fin de obtener la información más actualizada sobre el tema, además de incluir un periodo de tiempo anterior y posterior a la firma del acuerdo de paz en Colombia; (c) que fueran documentos cuya población objetivo eran las víctimas del conflicto armado en Colombia; (d) que tuvieran como finalidad los temas del duelo y los sentimientos morales relacionados de manera directa o indirecta con la población mencionada;y (e) se tuvieron en cuenta las diferentes disciplinas científicas desde las cuales se realizaron dichos estudios.

La tercera fase permitió la sistematización documental por medio del software Atlas.ti. En esta se recopilaron todos los textos que cumplieron con los criterios de selección expuestos en la segunda fase. Los documentos recopilados provienen de bases de datos indexadas, repositorios y directorios de revista (Proquest, Scopus, Ebsco, Dialnet, Jstor, Science Direct, Scielo, Redalyc, Web Of Science, Clacso, Doaj) que contienen información 
relevante, actualizada, precisa, contrastada y de calidad. Además, se incluyó en la búsqueda los repositorios de las universidades que dieron acceso a tesis de maestría y doctorado sobre el tema.

La cuarta fase consistió en la operacionalización de las categorías de análisis. Se partió de lo más general a lo más específico, para lo cual se utilizó un sistema de códigos y redes axiales elaboradas con la ayuda del software Atlas.ti. En la quinta y última fase se utilizó la información documental recogida, más la operacionalización realizada, para la sistematización y el análisis de la información, lo que arrojó como resultado dos categorías de análisis. La primera referida al duelo en los sobrevivientes del conflicto armado presenta una aproximación a posturas teóricas, metodológicas y perspectivas de investigación; la segunda, relacionada con las investigaciones realizadas sobre los sentimientos morales en sobrevivientes del conflicto armado en Colombia da cuenta de la conceptualización de los sentimientos morales y su abordaje en esta población.

\section{Resultados}

El 75,4\% de las referencias de este artículo corresponde a bibliografía recopilada entre el 2014 y el 2019 , y el
4I,5\% pertenece al periodo 2017-2019. En la revisión se encontró un total de 35 investigaciones realizadas en Colombia que cumplían con todos los criterios de inclusión definidos en la metodología, los cuales provienen de diversas disciplinas tales como filosofía, economía, derecho, psicología, medicina, sociología y neurociencias. Entre los documentos recuperados se hallan artículos resultados de investigaciones aplicadas, artículos de revisión y reflexión, así como tesis de maestría, información que se describe en la tabla I. Las demás referencias bibliográficas sirvieron de base para la conceptualización de las categorías de análisis.

El 9|,4\% de estas investigaciones son estudios cualitativos, de modo que es este el enfoque más utilizado para indagar sobre el duelo y los sentimientos morales en las víctimas del conflicto armado.

\section{El duelo en sobrevivientes del conflicto armado colombiano}

En el 20I5, Gallego y Burgos (2015) tuvieron un acercamiento a la experiencia de algunos actores que presenciaron la toma de la guerrilla al corregimiento Arboleda, en Caldas, en contra de la Policía Nacional, considerado uno de los actos más crueles ocurridos en el 2000. Estos autores identificaron múltiples secuelas generadas en las

Tabla I. Investigaciones referenciadas periodo 2014-2019

\begin{tabular}{|c|c|c|c|c|}
\hline N. ${ }^{\circ}$ & Título & Tipología & Ciudad/país & Autor(es) \\
\hline I & $\begin{array}{l}\text { Memoria, arte y duelo: el caso del Salón del Nunca } \\
\text { Más de Granada (Antioquia, Colombia) }\end{array}$ & Enfoque cualitativo & Antioquia & Rubiano (20I7a) \\
\hline 2 & $\begin{array}{l}\text { El apoyo social percibido por las víctimas del conflicto } \\
\text { armado en Colombia }\end{array}$ & Enfoque cuantitativo & $\begin{array}{l}\text { Barrancabermeja, } \\
\text { Trujillo, Bello, Montería } \\
\text { y Santa Marta }\end{array}$ & Echeverri et al. (2018) \\
\hline 3 & $\begin{array}{l}\text { De víctimas a sobrevivientes: la fuerza poiética y } \\
\text { resiliente del cuidar }\end{array}$ & $\begin{array}{l}\text { Enfoque cualitativo, } \\
\text { artículo de reflexión }\end{array}$ & Colombia & Comins (2015) \\
\hline 4 & $\begin{array}{l}\text { De víctimas a sobrevivientes: implicaciones para la } \\
\text { construcción de paces en Colombia }\end{array}$ & $\begin{array}{l}\text { Cualitativo, artículo } \\
\text { de reflexión }\end{array}$ & Manizales & Bustamante (2017) \\
\hline 5 & $\begin{array}{l}\text { Formación en herramientas terapéuticas a sobrevivi- } \\
\text { entes del conflicto armado en el Pacífico colombiano: } \\
\text { reflexividad y cuidado de sí }\end{array}$ & $\begin{array}{l}\text { Enfoque cualitativo, } \\
\text { basado en entrevistas } \\
\text { semiestructuradas y } \\
\text { grupos focales }\end{array}$ & $\begin{array}{l}\text { Quibdó y } \\
\text { Buenaventura }\end{array}$ & Aranguren y Rubio (2018) \\
\hline 6 & $\begin{array}{l}\text { La atención psicosocial a personas víctimas del conflicto } \\
\text { armado en contextos institucionales de salud pública }\end{array}$ & $\begin{array}{l}\text { Enfoque cualitativo, } \\
\text { artículo de reflexión }\end{array}$ & Colombia & Obando, Salcedo y Correa (2017) \\
\hline 7 & $\begin{array}{l}\text { Psicología de la salud en el contexto del conflicto } \\
\text { armado en Colombia: un marco de referencia }\end{array}$ & $\begin{array}{l}\text { Enfoque cualitativo, } \\
\text { artículo de revisión }\end{array}$ & Colombia & $\begin{array}{c}\text { Cerquera, Peña, García, Orejuela } \\
\text { y García (2017) }\end{array}$ \\
\hline 8 & $\begin{array}{l}\text { Vicisitudes de los proyectos institucionales de atención } \\
\text { psicosocial a víctimas del conflicto armado colombiano }\end{array}$ & $\begin{array}{l}\text { Enfoque cualitativo, } \\
\text { entrevistas } \\
\text { semiestructuradas }\end{array}$ & Colombia & $\begin{array}{l}\text { Villa, Arroyave, Montoya, Y } \\
\text { y Muñoz (2017) }\end{array}$ \\
\hline 9 & $\begin{array}{l}\text { Las pérdidas y los duelos en personas afectadas por } \\
\text { el desplazamiento forzado }\end{array}$ & $\begin{array}{l}\text { Enfoque cualitativo, } \\
\text { entrevistas } \\
\text { semiestructuradas }\end{array}$ & Medellín & Díaz et al. (20I5) \\
\hline
\end{tabular}


Tabla I. Investigaciones referenciadas periodo 2014-2019

\begin{tabular}{|c|c|c|c|c|}
\hline N. ${ }^{\circ}$ & Título & Tipología & Ciudad/país & Autor(es) \\
\hline 10 & $\begin{array}{l}\text { Las víctimas, la memoria y el duelo: el arte contem- } \\
\text { poráneo en el escenario del postacuerdo }\end{array}$ & $\begin{array}{l}\text { Enfoque cualitativo, } \\
\text { artículo de reflexión }\end{array}$ & Colombia & Rubiano (20I7b) \\
\hline 11 & $\begin{array}{l}\text { El duelo en contextos de violencia: aportes desde el } \\
\text { psicoanálisis y la perspectiva transcultural }\end{array}$ & $\begin{array}{l}\text { Enfoque cualitativo, } \\
\text { artículo de reflexión }\end{array}$ & Colombia & Mercado (2017) \\
\hline 12 & Malestar psicológico en víctimas del conflicto armado. & $\begin{array}{l}\text { Enfoque cualitativo, } \\
\text { artículo de revisión }\end{array}$ & Colombia & Cudris-Torres, Barrios Núñez (2018) \\
\hline 13 & $\begin{array}{l}\text { Afectaciones psicológicas, estrategias de afrontamiento } \\
\text { y niveles de resiliencia de adultos expuestos al conflic- } \\
\text { to armado en Colombia }\end{array}$ & Enfoque cuantitativo & Bogotá & $\begin{array}{l}\text { Hewitt, Juárez, Parada, Guerrero, } \\
\text { Romero, Salgado y Vargas (2016) }\end{array}$ \\
\hline 14 & $\begin{array}{l}\text { Secuelas psicológicas de la guerra en mujeres forzadas } \\
\text { a desplazarse }\end{array}$ & $\begin{array}{l}\text { Enfoque cualitativo, } \\
\text { artículo de revisión }\end{array}$ & Colombia & $\begin{array}{c}\text { Andrade, Alvis, Jiménez, Redondo } \\
\text { y Rodríguez (2016) }\end{array}$ \\
\hline 15 & $\begin{array}{l}\text { Sentimientos morales, educomunicación y nuevas } \\
\text { ciudadanías en el Colectivo Caminos de Paz }\end{array}$ & $\begin{array}{l}\text { Enfoque cualitativo } \\
\text { y método biográfico } \\
\text { narrativo }\end{array}$ & Bogotá & Bernal y Ramos (2015) \\
\hline
\end{tabular}

16 Simpatía, resentimiento y perdón: un análisis del rol Enfoque cualitativo del resentimiento en la TMS de Adam Smith

Bogotá $\quad$ Rodríguez (2017)

Emociones en niños, niñas y adolescentes desde la Enfoque cualitativo,

17 experiencia del desplazamiento y la vinculación a los metodología estado grupos armados en Colombia del arte

Colombia Guzmán et al. (2016)

Apoyo mutuo, liderazgo afectivo y rehabilitación Enfoque cualitativo,

18 comunitaria. Una experiencia de acompañamiento con implementación psicosocial para la rehabilitación de víctimas del de grupos focales conflicto armado

Medellín Villa et al. (2016)

Comprensiones de perdón, reconciliación y justicia Enfoque cualitativo,

en víctimas de desplazamiento forzado en Colombia empleando el método

de teoría

fundamentada

Cundinamarca Castrillón, Riveros, Knudsen, López,

Cundinamarca Correa y Castañeda (2018)

$\begin{array}{ll}\text { Perdón y reconciliación: una perspectiva psicosocial Enfoque cualitativo, } \\ \text { desde la noviolencia } & \text { artículo de reflexión }\end{array}$

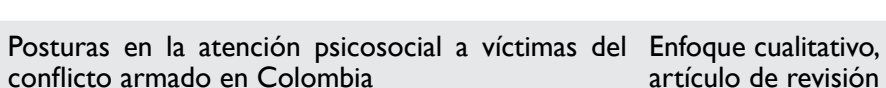

20 desde la noviolencia

articulo de revision

Procesos organizativos de mujeres y víctimas del Enfoque cualitativo,

22 conflicto armado y relaciones con la democracia local artículo de reflexión en el Oriente Antioqueño
Colombia
Villa (2016)

Colombia Moreno y Díaz (2016)

Colombia Hoyos y Nieto García (2017)

Orientaciones emocionales colectivas sobre el con- Enfoque cualitativo,

23 flicto armado y sus actores como barreras para la entrevistas a

construcción de la paz y la reconciliación en ciu- profundidad, dadanos de Medellín.

semiestructuradas

Medellín

Villa, Rúa, Serna, Barrera Machado y Estrada (2019)

Transformación de las emociones en las víctimas del Enfoque cualitativo

24 conflicto armado para la reconciliación en Colombia

25 Las emociones en el proceso de paz colombiano

Enfoque cualitativo, artículo de reflexión

La repugnancia: una emoción política en el conflicto Enfoque cualitativo, armado colombiano

artículo de reflexión

Polivictimización por el conflicto armado y sufrimien- Enfoque cuantitativo

27 to emocional en el departamento del Magdalena, Colombia

Enfoque cuantitativo

Relaciones entre las emociones en víctimas del conflicto armado y sus procesos de reparación

Enfoque cualitativo, tesis de maestría

$\begin{array}{ll}\begin{array}{l}\text { Desaparición forzada en Colombia: el duelo, un asunto Enfoque cualitativo, } \\ \text { de reparación social }\end{array} & \text { artículo de reflexión }\end{array}$ $\begin{aligned} & \text { Desaparición forzada en Colombia: el duelo, un asunto Enfoque cualitativo, } \\ & \text { de reparación social }\end{aligned}$
artículo de reflexión

29 de reparación social 
Tabla I. Investigaciones referenciadas periodo 20I4-20I9

\begin{tabular}{|c|c|c|c|c|}
\hline $\mathbf{N} .^{\circ}$ & Título & Tipología & Ciudad/país & Autor(es) \\
\hline 30 & $\begin{array}{l}\text { Caso emblemático, corregimiento Arboleda- Caldas. } \\
\text { Año } 2000 .\end{array}$ & $\begin{array}{l}\text { Enfoque cualitativo, } \\
\text { entrevista a } \\
\text { profundidad }\end{array}$ & Colombia & Gallego y Burgos (2015) \\
\hline 31 & $\begin{array}{l}\text { Narrativas femeninas del conflicto armado y la violencia } \\
\text { política en Colombia: contar para rehacerse }\end{array}$ & Enfoque cualitativo & Colombia & Herrera y Pertuz (20I5) \\
\hline 32 & $\begin{array}{l}\text { Victimario: la víctima desconocida del conflicto armado } \\
\text { colombiano.Análisis de su reparación en torno al prin- } \\
\text { cipio de igualdad }\end{array}$ & $\begin{array}{l}\text { Enfoque cualitativo, } \\
\text { alcance descriptivo, } \\
\text { investigación } \\
\text { documnetal }\end{array}$ & Colombia & Aguirre (2019) \\
\hline 33 & $\begin{array}{l}\text { Sentimientos morales y políticos en la formación } \\
\text { ciudadana en Colombia, atributos y estigmas }\end{array}$ & $\begin{array}{l}\text { Enfoque cualitativo, } \\
\text { análisis de narrativas }\end{array}$ & Colombia & Quintero y Mateus (20|4) \\
\hline 34 & $\begin{array}{l}\text { Imágenes en duelo: víctimas del conflicto armado } \\
\text { colombiano en la cámara de Erika Diettes }\end{array}$ & $\begin{array}{l}\text { Análisis de trabajos } \\
\text { fotográficos }\end{array}$ & Colombia & Cardona (2015) \\
\hline 35 & Memorias taciturnas del desarraigo y la territorialización & $\begin{array}{l}\text { Enfoque cualitativo, } \\
\text { hermenéutico, del } \\
\text { espectro artístico }\end{array}$ & Nariño & Portilla (2014) \\
\hline
\end{tabular}

víctimas, algunas de ellas ligadas a la dimensión psicológica, específicamente trastornos mentales, como, por ejemplo, el estrés postraumático y trastornos del sueño, además de conductas desadaptativas por el dolor de las pérdidas (p. ej., consumo de alcohol, de sustancias psicoactivas $y$ en el caso de la esposa de un policía desaparecido, al no tener noticias de su cuerpo, dificultades en la elaboración del duelo). Esto último permite hablar, además, de diferentes secuelas del conflicto e introduce así el lugar de la pérdida en la experiencia posterior a los hechos y su relación directa con el proceso de duelo.

En el abordaje de los procesos de duelo se encuentra que la pérdida se instituye como el acontecimiento sin el cual no sería posible hablar de este proceso, tal como se afirma en el trabajo de Díaz et. al. (2015) y se incluye en el desarrollo conceptual de autores como Neimeyer (Moreno, 2010) y Rando (Díaz, 2019).Así, las pérdidas en el contexto del conflicto armado colombiano podrían nombrarse como la principal consecuencia que el hecho victimizante ejerce sobre las víctimas, $y$, en este sentido, el significado de esta se configura por la relación vincular que se tenía con la persona, el objeto o el lugar, convirtiéndola en un componente que influyen en el proceso de elaboración del duelo (Díaz et al., 2015).

Al respecto, en Medellín se realizó un estudio con el fin de analizar los significados de diversas experiencias y de la elaboración del duelo en condiciones de desplazamiento forzado. En los relatos de las personas se encontraron sentimientos tales como el miedo, la ira, el rencor y el resentimiento hacia quienes ocasionaron los hechos $y$, por otra parte, la culpa y la vergüenza en cuanto afectos experimentados hacia ellos mismos. Se obtuvo como resultado que el desplazamiento, además de ocasionar pérdidas físicas y simbólicas, causa dolor, incertidumbre, desconfianza y comportamientos de aislamiento. Asimismo, influye en el proceso de elaboración del duelo, el cual depende de factores tales como el apoyo social, la disponibilidad y el acceso a factores simbólicos y económicos, y a las características propias de la persona (Díaz et al., 20I5).

En este sentido, hablar sobre el duelo enmarcado en el conflicto armado es hablar de la relación de la víctima con las secuelas del hecho victimizante, por lo que se encuentra una gran variedad de trabajos que se acercan a los procesos de elaboración del duelo asociados al hecho, tal como se evidencia en los estudios realizados por Portilla (20l4), Guzmán et. al. (2016) y Castrillón et. al. (20/8), los cuales abordan la pérdida del vínculo por razones de desaparición forzada o por masacres, en los que "el proceso queda interrumpido, pues no hay un cuerpo que velar. Los desaparecidos no están, propiamente, ni vivos ni muertos" (Rubiano, 2017a, p. 338). Así, entonces, la incertidumbre sobre la verdad queda alojada en la experiencia psíquica de la víctima indirecta, lo que dificulta su pronta resignificación $y$, por tanto, se convierte el hecho victimizante en una variable relevante en los estudios sobre duelo en sobrevivientes del conflicto armado.

De este modo, se abren intereses investigativos asociados al duelo en sobrevivientes del conflicto armado en Colombia que, en los últimos años, no solo han aumentado, sino que, además, han incluido diversos abordajes 
investigativos, algunos de los cuales pueden asociarse al campo sociológico/sociocultural y psicosocial, tal como se expresa en los dos siguientes apartados.

\section{Estudios socioculturales}

Como se expuso en la introducción de este estudio, existen diferentes marcos conceptuales que permiten entender el duelo y han servido de base para el desarrollo de trabajos investigativos. Entre estos se encuentra el sociológico o sociocultural, el cual tiene un énfasis en el arte, expresado este a través de técnicas estéticas, pictóricas y gráficas (Portilla, 2014), además del ritualismo y la construcción de memoria histórica.

Tal es el caso del abordaje realizado por Rubiano (2017a), titulado "El caso del Salón del nunca más en Granada, Antioquia", en el que se utilizaron imágenes fotográficas y se desarrollaron dispositivos visuales con el propósito de representar los hechos ocurridos y movilizar la memoria y no dejar en el olvido a las víctimas directas del conflicto, así como para reparar simbólicamente y ser fuente de canalización del dolor experimentado. Este tipo de estrategias abrieron el camino a la resignificación del hecho por medio del arte y la construcción de memoria (Rubiano, 2017a; Cardona, 2015), al hacerse visibles a través de prácticas artísticas. Otro ejemplo de estas estrategias es la obra Sumando ausencias, la cual es el cuarto acto de duelo en espacio público liderado por la artista Doris Salcedo. En esta un grupo de víctimas escribieron en telas blancas los nombres de 1900 víctimas del conflicto armado como una forma de expresar el dolor colectivo (Rubiano, 2017a). Sobre esta obra el autor refiere:

Se pone de manifiesto una diversidad de experiencias suscitadas por la construcción de una comunidad efímera en la que se dio un recorte de espacio y tiempo que, en última instancia, permitió construir un marco para simbolizar las pérdidas humanas del conflicto armado en Colombia. No hay duelo sin marco, es decir, sin procesos de simbolización y representación. (Rubiano, 2017a, p. 120)

Esto pone de manifiesto el valor de la simbolización en los procesos de elaboración del duelo y la construcción comunitaria de estrategias para representar y expresar el dolor vivido. En esta misma línea se encuentra la activación de la memoria colectiva como mecanismo que permite resignificar los hechos, adquirir posturas sociales y dar lugar a programas en pro de la reparación y cese del conflicto por medio de instituciones como, por ejem- plo, la Asociación Provincial de Víctimas a Ciudadanos (Aproviaci). En esta asociación se realizan actos comunitarios como el denominado "Por la luz", representando a través de velas encendidas la necesidad de vencer el miedo, tanto para rememorar la existencia real de la violencia como para recordar los recursos y alternativas que permiten enfrentar sus efectos (Guana, 20l0).

\section{Estudios psicosociales}

Algunos estudios se ocupan de interrogar la efectividad de los programas de intervención con población víctima del conflicto armado (Obando et al., 20I7), así como las dificultades que se pueden encontrar en la implementación de estos proyectos tanto para las víctimas como para los profesionales que realizan su implementación. Al respecto, Villa et al. (2017) muestran la importancia de evaluar la forma en que se han estructurado este tipo de proyectos, en asuntos tales como el componente económico y el diagnóstico de las necesidades reales de la población a intervenir, en los que es clave partir "desde abajo", es decir, desde la experiencia propia de las víctimas y no desde el establecimiento de prejuicios y lecturas externas que conllevan a no realizar acompañamientos de mayor efectividad para esta población.

Asimismo, se encuentran iniciativas dirigidas a la generación de acciones reparativas mediante la formación de líderes comunitarios (Aranguren \& Rubio, 2018) y la consideración de las experiencias propias según la población, como, por ejemplo, los enfoques de género, en los que se ha manifestado un interés en las vivencias de las mujeres en el conflicto (Andrade et al., 2016; Herrera \& Pertuz, 2015; Peltier \& Szwarcberg, 2019), y el lugar activo que ocupan en iniciativas sociales (Hoyos \& Nieto, 2017). Por otra parte, existen intereses en promover la toma de conciencia por parte de las víctimas a ser sujetos activos en la resignificación de los acontecimientos victimizantes (Moreno y Díaz, 2016; Villa et al., 2016;) y no sujetos pasivos que esperan respuestas externas como condicionantes a la elaboración del hecho. Es este último caso el que ha permitido que en algunos estudios se sugiera un cambio en la utilización del término víctima a la expresión sobreviviente (Bustamante, 2017) o "sujetos afectados por hechos de victimización” (Moreno \& Díaz, 20।6), en tanto hacen alusión a la persona que busca más allá de la compensación por parte del Estado, llegando a reconocer aspectos tales como la reconfiguración de su proyecto de vida y la reparación del daño subjetivo de manera autónoma. 
De igual forma, en los programas de intervención se evidencia que los procesos formativos son instancias para encontrar recursos que permitan afrontar y superar el dolor por medio de la instauración de la necesidad de ayudar a otros (Aranguren \& Rubio, 2018). Asimismo, se resalta la prevalencia de los grupos de apoyo como dispositivo en el cual las víctimas pueden expresar sus sentimientos y comenzar a verse unos a otros desde un plano que se dirija hacia su bienestar emocional (Villa, 20 I 3;Villa, 2016). Es así como se conforman instancias en las que el dolor se convierte en una oportunidad para el fortalecimiento del tejido social (Ruta Pacífica de las Mujeres, 20I3), y los procesos de perdón y reconciliación (Castrillón et al., 2018) como soportes que logran impactar de forma positiva en la reparación y la transformación social de las víctimas. Todos estos procesos sociales facilitan el trabajo para enfrentar el sufrimiento colectivo y avanzar en el afrontamiento o elaboración del sufrimiento propio.

Además, se encuentran antecedentes que emplean el uso de la narrativa (Cerquera et al., 2017) por medio de relatos de vida (Villa, 2013) o la narrativa autobiográfica (Bernal \& Ramos, 20I5), así como la entrevista semiestructurada (Villa et al., 2019) y los grupos focales o grupos de discusión (Aranguren \& Rubio, 2018; Villa et al., 2016) como herramientas de generación de información y de expresión emocional, dado que son instrumentos que se consideran opciones de mayor recurrencia metodológica al indagar sobre el duelo y los procesos de intervención con las víctimas.

El duelo se admite como una de las posibles secuelas emocionales ocasionadas por el conflicto, no obstante, algunos trabajos también refieren la presencia de trastornos mentales o experiencias traumáticas que han producido malestar psicológico en la víctima, como, por ejemplo, el trastorno de estrés postraumático, depresión mayor, trastorno adaptativo y trastorno por estrés agudo, entre otros, lo que a su vez se ha reflejado en trabajos de intervención psicosocial y promoción de la salud mental en esta población (Cudris \& Barrios, 2018; Hewitt et al., 2016).

Vale la pena señalar que estos trabajos no siguen una postura hermética para abordar el duelo, ya que algunos logran integrar elementos asociados tanto al campo sociocultural como al psicosocial, y en algunos casos se incluyen otros campos, como, por ejemplo, el psicoanalítico. Esto puede constatarse en el estudio de Mercado (2017), el cual se ocupó de reflexionar sobre factores que entran en juego en el proceso de elaboración del duelo cuando las personas aún se encuentran inmersas en entornos afectados por la violencia, así como los retos a los que se someten psicólogos y otros profesionales para realizar intervenciones ante estas circunstancias, y la adopción de estrategias de tramitación simbólica de la pérdida (como, por ejemplo, el ritualismo para dar cuerpo al ser fallecido o desaparecido, hacer justicia y prevenir la venganza).

En asociación con el deseo de justicia y venganza existe una variedad de emociones tales como la rabia, la impotencia, la culpa, el resentimiento y el miedo, entre otros, que expresan su afectación emocional por los eventos a los que fueron expuestos (Grupo de Memoria Histórica [GMH], 20I3). Autores como López (20I3) realizaron un acercamiento a estas experiencias emocionales de las víctimas priorizando el valor de "las teorías de los sentimientos morales en la preparación de un posible proceso de reconciliación, que pase por la experiencia liberadora del perdón por parte de las víctimas y de la solidaridad por parte de la sociedad civil" (p. 85). Es por esta razón que el conocimiento de los sentimientos morales emergentes en marcos de conflicto puede ser un medio de identificación de obstáculos o, por el contrario, de recursos mentales, en los que la víctima pueda superar el grado de dolor emocional que el conflicto ha dejado en sí misma.

\section{Los sentimientos morales en sobrevivientes}

\section{del conflicto armado colombiano}

Dentro de la revisión documental de las investigaciones sobre los efectos del conflicto armado colombiano se encuentran aquellas que abordan las emociones $y$ los sentimientos, las cuales realizan un acercamiento al conocimiento sobre la experiencia subjetiva de los actores involucrados dentro del conflicto, entre ellos los victimarios (Aguirre, 2019) y las víctimas (Díaz et al., 20I5). Sin embargo, existe un mayor énfasis en estos últimos, a fin de profundizar en sus procesos vividos antes, durante y después de los hechos, debido al dolor emocional ocasionado y a las múltiples consecuencias que puedo dejar en la víctima (Ospino et al., 2017). En este sentido, se han originado cuestionamientos sobre el lugar que ocupan los sentimientos morales en el proceso de reparación y reconciliación de los sobrevivientes frente al acto victimizante.

Algunos estudios han abordado los sentimientos morales con población cercana a marcos de conflicto, tal es el caso del sentimiento de justicia en un estudio realizado por Quintero y Vasco (2007) con jóvenes universitarios y 
jóvenes desplazados, orientado a conocer sus posturas y sentimientos morales sobre acciones valoradas por ellos como justas e injustas por medio de la entrevista no estructurada y semiestructurada o la biografía narrativa. Entre los resultados se encuentran controversias acerca del perdón en actos de injusticia tales como los crímenes de lesa humanidad y la importancia de recordar los actos sociales de injusticia para no dejarlos en el olvido. Los autores concluyen que, por medio de sus expresiones sobre temas de justicia, logran manifestar principios, valores y creencias.

Otro estudio se llevó a cabo con niños, niñas y jóvenes del Colectivo Caminos de Paz en la Ciudad de Bogotá, algunos de ellos víctimas del conflicto armado en Colombia. Se utilizó el método biográfico narrativo con el fin de describir los sentimientos morales expresados en las prácticas educomunicativas de los participantes. Se encontró que los sentimientos morales contribuyen a la formación de nuevas ciudadanías a través de los valores que se van adquiriendo en la cultura escolar.Además, se afirma la importancia de la educación en sentimientos morales, como, por ejemplo, la compasión, a fin de reconocer la propia vulnerabilidad y la de los demás y, con ello, contribuir a una mayor justicia social (Bernal \& Ramos, 2015).

Ahora bien, algunos estudios se han interesado por analizar los sentimientos morales desde el diálogo con postulaciones teóricas. Tal es el caso del resentimiento, una emoción moral que, según el filósofo Strawson, "aparece ante las ofensas que inflige una persona a otra" (Ortiz, 2015 , p. 952). Es por esto que en situaciones de conflicto se presenta como reacción de la víctima hacia el agresor, lo que abre el interrogante sobre su posibilidad de transformarlo o afrontarlo.Al respecto, Rodríguez (2017), en su investigación "simpatía, resentimiento y perdón: un análisis del rol del resentimiento en la TSM de Smith", afirma que el resentimiento es un tema de actual discusión filosófica en lo concerniente a las posibilidades de establecer procesos de perdón y reconciliación. De este modo, plantea la tesis de que el resentimiento puede superarse y cambiar la relación entre el agresor y la víctima a través de la "simpatía mutua". En este mismo estudio, el autor aborda la simpatía desde los planteamientos de Smith a fin de tratar la importancia de solidarizarse con el sufrimiento de la víctima, lo que hace posible una mayor superación de los efectos de la violencia.

Los sentimientos y las emociones en el conflicto se presentan como dispositivos que permiten a la persona estar en relación con el contexto a través de su experiencia subjetiva, creencias, posturas y acciones que surgen de manera singular en estos escenarios. De igual manera, la investigación sobre las emociones en marcos sociopolíticos de guerra ha permitido indagar no solo por la experiencia individual, sino por el lugar que ocupan en la configuración de marcos culturales y sociales. Algunos estudios se han interesado en profundizar sobre estos aspectos desde diferentes perspectivas (Cardona, 2019; Marín, 2018; Valencia, 2017; Villa et al., 2019). En Medellín, Villa et al. (2019) indagaron por las orientaciones emocionales de algunos ciudadanos frente al proceso de negociación entre el Gobierno y las Fuerzas Armadas Revolucionarias de Colombia (FARC), identificando emociones como la indignación, la ira y el odio hacia estos grupos armados, y emociones positivas de admiración, orgullo y sentimiento de patriotismo hacia la Fuerza Pública. Asimismo, se encontraron emociones positivas como la esperanza y la empatía en quienes se interesan por la transformación social a través del apoyo a los acuerdos, atenuando la búsqueda de acciones transformadoras como, por ejemplo, los actos de solidaridad hacia las víctimas del conflicto armado. Esto permite comprender el tipo de sentimientos que tienen los ciudadanos frente a los actores del conflicto, los cuales están basados en el accionar y los imaginarios sociales generados por dichos actores y que permiten la configuración de emociones positivas o negativas en los ciudadanos.

En esta misma línea, Castrillón et al. (2018) realizaron un estudio en el departamento de Cundinamarca con el propósito de conocer la comprensión que tenían las víctimas del desplazamiento forzado acerca del concepto del perdón, la reconciliación y la justicia. Se identificó que los participantes conciben el primero como la capacidad de convertir los sentimientos negativos en positivos y olvidar el acontecimiento victimizante. El segundo se asoció con la capacidad de reestructurar los vínculos que se tienen y el tercero a un acto dado por Dios y una condición sin la cual no sería posible reconciliar y perdonar.

Sobre la transformación de las emociones de las víctimas se han constituido instancias como el programa de Escuelas de Perdón y Reconciliación (Espere) de la Fundación Paz y Reconciliación. Sobre este, Peltier y Szwarcberg indagaron en el 2019 sobre el papel de los sentimientos $y$ las experiencias emocionales en el posacuerdo, evidenciando que a través del programa se encuentran nuevas alternativas de pensamiento dirigidas a establecer una 
mayor gestión de las emociones y, con ello, nuevas actitudes sociales, como, por ejemplo, la humanización de los actores del conflicto:

Romper con la cultura del enemigo, tan difundida en los tiempos de guerra, significa deshacerse de las ideas de venganza, de odio o de indiferencia [...]. Tras las Espere, las mujeres tienen posibilidades de construir historias quitando los sentimientos de venganza o de odio. Unas de las mujeres de María La Baja da testimonio de que "a veces decimos cosas que no queremos decir por culpa de la rabia, así dialogar es importante". Para evitar sobrepasar los límites de los pensamientos, se proveen herramientas para elaborar narrativas alternativas que no se inscriben en la perspectiva binaria clásica de amigo-enemigo. Primero, se enfatiza la idea de humanidad: aunque los ofensores son responsables de hechos que destruyeron las vidas de las víctimas, se promueve la humanización de todos los individuos, incluyendo a los ofensores. (Peltier \& Szwarcberg, 2019, p. 220)

Así, pues, se encuentran sentimientos morales de vengan$\mathrm{za}$, odio, indiferencia y rabia que, desde el planteamiento de Smith (1759), están basados en la aprobación o desaprobación de una conducta, en este caso frente a los victimarios. Es por medio de instancias que viabilicen la incorporación de nuevas narrativas y la configuración de otras formas de pensamiento que se hace posible el establecimiento de cambios en la experiencia subjetiva de los sobrevivientes.

En la actualidad no existe unanimidad en el estudio de los sentimientos morales en víctimas, mientras que con relación al duelo se identifica un menor desarrollo de trabajos enfocados en esta categoría. No obstante, se evidencian intereses investigativos que de manera implícita los han abordado, encausados a la comprensión y transformación de las emociones. Esto podría dar lugar al desarrollo posterior de investigaciones con mayor focalización en los sentimientos morales y la formación de estos, hacia el perdón y la reconciliación (Villa, 2016) como alternativa que podría favorecer los procesos de reparación integral que el Estado ha promulgado para quienes han sido víctimas del conflicto armado.

\section{Conclusiones}

Los estudios que interrogan sobre el proceso de duelo al que se ven sometidas las víctimas luego de los hechos (Díaz et al., 20I5; Rubiano, 2017a) demuestran una relación directa con la manifestación de sentimientos morales tales como el resentimiento, el rencor, la ira, el dolor la indignación y la justicia, sentimientos que son comunes al indagar tanto por el duelo como por los sentimientos morales. Esto permite afirmar la existencia de una vinculación y relación directa entre ambas categorías de análisis.

En los trabajos rastreados sobre duelo en víctimas no se encontraron estudios que se enfoquen en clasificar la experiencia en periodos o fases por las cuales podrían pasar las víctimas, evidenciándose un mayor interés por el acercamiento a la vivencia singular que se ha generado en los grupos poblacionales de estudio a través de relatos de vida o la biografía narrativa, entre otras herramientas, con el propósito de lograr un acercamiento a la experiencia subjetiva para un mayor conocimiento y comprensión de la realidad psíquica que viven los sobrevivientes.

Con relación a los sentimientos morales se encuentra que, si bien se han realizado estudios aplicados que abordan estos temas en víctimas directas e indirectas del conflicto armado en Colombia (Bernal \& Ramos, 2015; Castrillón et al., 2018; Guzmán et al., 2016), se hace necesario promover estudios que se dediquen a ahondar en esta categoría de análisis desde la variedad de sentimientos morales que pueden presentar las víctimas del conflicto a partir del daño emocional y moral que dejan las huellas de la violencia, con la finalidad de favorecer procesos de perdón y reconciliación que se diseñen mediante planes y programas de intervención.

Asimismo, no se halla un consenso en las perspectivas teóricas dirigidas al estudio de los sentimientos morales en población víctima del conflicto armado colombiano, dado que es este un tema que debe ser abordado desde diferentes disciplinas y enfoques metodológicos. De igual manera, $y$ aunque no se encuentra un consenso en dichos planteamientos, sí se encuentra un común denominador en admitir la importancia de profundizar en el componente afectivo de quienes han sufrido de forma directa las secuelas de los hechos victimizantes, en tanto posibilita descubrir sus posturas sociales, sus estrategias de afrontamiento y los recursos internos que contribuyan más allá de la reparación económica a la reparación del daño moral o emocional (Cardona, 2019) como factor sustancial de los procesos de paz y reconciliación.

Con base en los antecedentes revisados se puede inferir que ambas dimensiones no se han estudiado de manera 
conjunta, pero sí tienen una relación implícita que puede cobrar interés al avanzar en la comprensión de la vivencia de las víctimas con relación a la resignificación de los acontecimientos y sus experiencias y posturas posteriores al hecho de victimización, como el caso de las personas que han sido despojadas de sus tierras, las víctimas de desaparición forzada o quienes viven en contextos que aún afecta la violencia. Esto abre el interrogante sobre cómo se puede tramitar el duelo ante estos escenarios y cómo, ante estas situaciones, se han ido configurando los sentimientos morales. La respuesta es un factor que impacta en las posturas sociales y los esfuerzos por buscar un bienestar social y emocional.

\section{Referencias}

Aguirre, J. E. (2019).Victimario: la víctima desconocida del conflicto armado colombiano. Análisis de su reparación en torno al principio de igualdad. Revista Derecho del Estado, 43, 291-320. https://doi.org//0.18601/01229893.n43.1 I

Andrade, J., Alvis, L., Jiménez, L., Redondo, M., \& Rodríguez, L. (20/6). Secuelas psicológicas de la guerra en mujeres forzadas a desplazarse. Revista Internacional de Psicología, I5(I), I-62.

Aranguren, J., \& Rubio, N. (20I8). Formación en herramientas terapéuticas a sobrevivientes del conflicto armado en el Pacífico colombiano: reflexividad y cuidado de sí. Revista de Estudios Sociales, 66, 18-29. https://doi.org//0.7440/ res66.2018.03

Bernal, A., \& Ramos, W. (20I5). Sentimientos morales, educomunicación y nuevas ciudadanías en el Colectivo Caminos de Paz. Infancias Imágenes, I 4(I), 23-39.

Bustamante,V. (2017). De víctimas a sobrevivientes: implicaciones para la construcción de paces en Colombia. Revista de Sociología y Antropología:Virajes, 19(I), I47-163. https://doi. org/10.17151/rasv.2017.19.1.8

Cardona, L. (2015). Imágenes en duelo: víctimas del conflicto armado colombiano en la cámara de Erika Diettes. Aletheia, 5(10). Recuperado de http://www.memoria.fahce. unlp.edu.ar/art_revistas/pr.6689/pr.6689.pdf

Cardona, N. (2019). Relaciones entre las emociones en víctimas del conflicto armado y sus procesos de reparación (Tesis de maestría). Medellín: Universidad de Antioquia.

Castrillón, L., Riveros,V., María, K., López,W., Correa,A., \& Castañeda, J. G. (20|8). Comprensiones de perdón, reconciliación y justicia en víctimas de desplazamiento forzado en Colombia. Revista de Estudios Sociales, 63, 84-98. https:// dx.doi.org/I0.7440/res63.20I8.07
Cerquera, A., Peña, A., García, C., Orejuela, D., \& García, M. (2017). Psicología de la salud en el contexto del conflicto armado en Colombia: un marco de referencia. Psicogente, 20(37), $|8|-19 \mid$.

Comins, I. (2015). De víctimas a sobrevivientes: la fuerza poética y resiliente del cuidar. Revista UAEM, 67, 35-54.

Corte Constitucional de Colombia. (2012). Relatoría C-052-12.

Corte Constitucional de Colombia. Sentencia C-052-12. (MP: Nilson Pinilla Pinilla, 8 de febrero de 2012).

Cudris, L., \& Barrios, A. (2018). Malestar psicológico en víctimas del conflicto armado. Revista CS, 26, 75-90.

Díaz, V. (2008). Del dolor al duelo: límite al anhelo frente a la desaparición forzada. Affectio Societatis, 9, I-20.

Díaz, V. (2019). La escritura del duelo. Colombia: Ediciones Uniandes y Universidad Eafit.

Díaz,V., Molina,A., \& Marín, M.A. (2015). Las pérdidas y los duelos en personas afectadas por el desplazamiento forzado. Pensamiento Psicológico, I3(1).

Echeverri, M. C., Moreno, J. C., Carrasco, N. E., Ferrel, F. R, \& Ferrel, L. F. (2018). El apoyo social percibido por las víctimas del conflicto armado en Colombia. El Ágora USB, 18(2), 362-373. https://doi.org// 0.21500/I6578031.3387

Freud, S. (198I). Duelo y melancolía. En Obras completas. Madrid: Biblioteca Nueva.

Gallego, M. L., \& Burgos, O. (2015). Caso emblemático, corregimiento Arboleda-Caldas. Año 2000. Revista Logos Ciencia \& Tecnología, 6(3), 63-73. https://doi.org// 0.22335/rlct. v6i3.39I

(GMH) Grupo de Memoria Histórica (2013). ¡Basta ya! Colombia: memorias de guerra y dignidad. Bogotá: Imprenta Nacional.

Guana,A. (2010). Del dolor a la propuesta, voces del panel de víctimas. Revista de Estudios Sociales, 36, I I4-125.

Guzmán, K., Fernández, M. C., \& Villalba, L.Y. (20I6). Emociones en niños, niñas y adolescentes desde la experiencia del desplazamiento y la vinculación a los grupos armados en Colombia. Panorama, I0(19), 85-96.

Herrera, M. C., \& Pertuz, C. (20I5). Narrativas femeninas del conflicto armado y la violencia política en Colombia: contar para rehacerse. Revista de Estudios Sociales, 53, I50- 162.

Hewitt, N., Juárez, F., Parada, A. J., Guerrero, J., Romero, Y. M., Salgado, A. M., \& Vargas, M.V. (2016). Afectaciones psicológicas, estrategias de afrontamiento y niveles de resiliencia de adultos expuestos al conflicto armado en Colombia. 
Revista Colombiana de Psicología, 25(I), I25- I 40. https://doi. org/I0.15446/rcp.v25n I.49966

Hoyos, G. (2007). Trampas a la moral. En E. Durán, \& I. Torrado, Derechos de los niños y las niñas. Debates, realidades y perspectivas (pp. 335-34I). Bogotá: Universidad Nacional de Colombia.

Hoyos, D., \& Nieto, A. (2017). Procesos organizativos de mujeres y víctimas del conflicto armado y relaciones con la democracia local en el Oriente Antioqueño. Desafios, 29(I), 139-175. https://doi.org// 0.12804/revistas.urosario. edu.co/desafios/a.4484

López, E. (2013). Perdonar sí, olvidar no, una aproximación a la reconciliación en Colombia desde los sentimientos morales. Universitas PhilosoPhica, 6 I (30), 85-96.

Marín, M. (2018). La repugnancia: una emoción política en el conflicto armado colombiano. Antrópica-Revista de Ciencias Sociales y Humanidades, 4(7), 4I-55.

Mercado, D. (2017). El duelo en contextos de violencia: aportes desde el psicoanálisis y la perspectiva transcultural. Lumen Gent, I(I), 35-43.

Moreno, E. (2010). El duelo por muerte, estado de la cuestión y revisión de la intervención psicoterapéutica (Trabajo de maestría). Barcelona: ISEP.

Moreno, M., \& Díaz, M. (20।6). Posturas en la atención psicosocial a víctimas del conflicto armado en Colombia. AGO. USB, 16(I), 13-57.

Nussbaum, M. C. (2014). Emociones políticas ¿por qué el amor es importante para la justicia? Barcelona: Paidós.

Obando, L., Salcedo, M., \& Correa, L. (2017). La atención psicosocial a personas víctimas del conflicto armado en contextos institucionales de salud pública. Psicogente, 20(38), 382-397. https://doi.org//0.1708I/psico.20.38.2559

Ospino, A., Guerra, V., \& Caamaño, B. (2017). Polivictimización por el conflicto armado y sufrimiento emocional en el departamento del Magdalena, Colombia. Revista Colombiana de Psiquiatría, 46(3), I47-I53.

Ortiz, E. (2015). Sentimientos morales, amor y libertad. Un examen de la propuesta compatibilista de Peter Strawson. Pensamiento, 7 I (268), 949-969.

Peltier, L., \& Szwarcberg, M. (2019).Transformación de las emociones en las víctimas del conflicto armado para la reconciliación en Colombia. Desafios, 3 I (2), 197-229. https://doi. org/I0.12804/revistas.urosario.edu.co/desafios/a.7283
Portilla, F. J. (20/4). Memorias taciturnas del desarraigo y la territorialización. Sophia, I0(I), 39-49.

Quintero, M., \& Vasco, E. (2007). Justificaciones y sentimientos morales de jóvenes universitarios y jóvenes desplazados acerca de las acciones justas e injustas. Acta Colombiana de Psicología, I0(I), 99-110.

Quintero, M., \& Mateus, J. (20I4). Sentimientos morales y políticos en la formación ciudadana en Colombia, atributos y estigmas. Folios, 39, |3-7|.

Rodríguez, J. (2017). Simpatía, resentimiento y perdón: un análisis del rol del resentimiento en la TSM de Smith. Universitas Philosophica, 68(34), 198-218.

Rubiano, E. (2017a). Memoria, arte y duelo: el caso del Salón del Nunca Más de Granada (Antioquia, Colombia). Historelo Revista de Historia Regional y Local, 9(18), 313-343. https://doi.org//0.15446/historelo.v9n I8.59106

Rubiano, E. (20I7b). Las víctimas, la memoria y el duelo: el arte contemporáneo en el escenario del postacuerdo. Anal. político, 30(90), I03-120.

Ruta Pacífica de las Mujeres. (20/3). La verdad de las mujeres en el conflicto armado colombiano. Bogotá: Comisión de la Verdad y Memoria De Mujeres Colombianas.

Smith, A. (I759). La teoría de los sentimientos morales. Madrid. Alianza Editorial.

(UARIV]) Unidad para la Atención y Reparación Integral a las Víctimas (2019). Reporte general. Recuperado de https:// www.unidadvictimas.gov.co/es/registro-unico-de-victimas-ruv/37394

Valencia, D. (2017). Las emociones en el proceso de paz colombiano. Revista da Facultad de Direito UFPR, 62(I), 23I254.

Villa, J. D. (2013). Memoria, historia de vida y papel de la escucha en la transformación subjetiva víctimas/sobrevivientes del conflicto armado colombiano. AGO.USB, I 4(I), I 3-25.

Villa, J. D. (2016). Perdón y reconciliación: una perspectiva psicosocial desde la noviolencia. Polis, 43, I-26.

Villa, J. D., Londoño, N. M., Gallego, M., Arango, L. I., \& Rosso, M. (2016). Apoyo mutuo, liderazgo afectivo y rehabilitación comunitaria, Una experiencia de acompañamiento psicosocial para la rehabilitación de víctimas del conflicto armado. El Ágora USB, I6(2), 359-678. 
Villa, J. D.,Arroyave, L., Montoya,Y., \& Muñoz,A. (2017).Vicisitudes de los proyectos institucionales de atención psicosocial a víctimas del conflicto armado colombiano. Revista el Ágora, 17(1), 157-175.

Villa,J.D.,Rúa,S.,Serna,N.,Barrera,D.,\& Estrada,C.(2019).Orientaciones emocionales colectivas sobre el conflicto armado y sus actores como barreras para la construcción de la paz y la reconciliación en ciudadanos de Medellín. El Ágora USB, 19(I), 35-63. https://doi.org//0.21500/16578031.4122
Yaffe, L. (20I I). Conflicto armado en Colombia: análisis de las causas económicas, sociales e institucionales de la oposición violenta. Revista CS, 8, 187-208.

Zapata, L., Giraldo, J., Zuleta, A., \& Montoya, C. (2015). Desaparición forzada en Colombia: el duelo, un asunto de reparación social. Revista Poiésis, 30, 157-162. 